\title{
Product performance based on contact-condensing binders as a function of pressing parameters
}

\author{
V.V. Glukhovskyi (ORCID 0000-0003-3917-174X), I.V. Glukhovskyi (ORCID 0000-0003-3830-2891) \\ National Technical University of Ukraine “Igor Sikorsky Kyiv Polytechnic Institute”, aven. Peremogy, 37, Bldg. 21, \\ Kyiv, 03056, Ukraine \\ Tel.: +380672985775 \\ E-mail: lpchernyak@ukr.net
}

Article info: received 22.11.2019, revised 29.11.2019, accepted 20.12.2019

Glukhovskyi, V.V., Glukhovskyi, I.V. (2020) Product performance based on contact-condensing binders as a function of pressing parameters 1(46), DOI: 10.26909/csl.1.2020.1

The mechanism of contact-condensation solidification provides the formation of a solid rocky body in the event of contact between the microparticles of a substance of amorphous or unstable crystalline structure without changing its chemical composition as a result of physical surface phenomena. Therefore, to provide stronger contacts between the particles of such binders during their condensation, it is necessary to apply external pressure (compression).

The implementation of such binders is not linked to the timing of grieving. The curing process is carried out immediately at the time of contact between the particles of such binders. In the future, the strength of artificial stone increases in natural conditions and in water.

The results of studies of the dependence of the pressing parameters on the basic performance of the products based on the binder contact-condensation hardening are presented. It is established that in order to maximize the effective action of pressures, which provide plastic deformation during compaction and provide the most dense packing of powder particles, there is a limit of working pressures in the range from 40 to $150 \mathrm{MPa}$. It is shown that it is convenient to use mathematical expressions (extrusion equations) when analyzing the processes occurring during extrusion, which reveal a functional relationship between the pressure and the density of the material thus obtained. With the help of the equations of pressing, for each powder or group related to the physicochemical parameters of the powders, the most economical parameters of the pressing modes can be determined.

The data obtained for the compression pressure characterizing the action of plastic deformation for the test mixtures is in the pressure range from $32 \mathrm{MPa}$ to $158 \mathrm{MPa}$. Increasing the pressure above leads to the transition of plastic deformation into elastic deformation, in which the seal passes due to the destruction of particles under the action of high pressures.

Key words: binder contact-condensation hardening, parameters of the pressing modes.

\section{Експлуатаційні характеристики виробів на основі контактно-конденсаційних в'яжучих як функція параметрів пресування}

\section{В.В. Глуховський, І.В. Глуховський}

Національний технічний університет України “Київський політехнічний інститут імені Ігоря Сікорського”, Київ, Україна

Представлені результати дослідження залежності параметрів пресування на основні експлуатаційні характеристики виробів на основі в'яжучих контактно-конденсаційного тверднення. Встановлено, що для забезпечення максимально ефективної дії тиску, яке забезпечує пластичні деформації при ущільненні та забезпечує найбільш щільну упаковку частинок порошку, існує межа робочих тисків в інтервалі від 40 до 150 МПа. Показано, що при проведенні аналізу процесів які протікають при пресуванні доцільно використовувати математичні залежності (рівняння пресування), які розкривають функціональну залежність між тиском та густиною отриманого матеріалу. За допомогою рівняння пресування для кожного порошку або групи близьких за фізико-механічними параметрами порошків можливо встановити найбільш економічні параметри режимів пресування. 


\section{Вступ}

В'яжучими контактно-конденсаційного твердіння називаються силікатні дисперсні системи аморфної та нестабільної кристалічної структури, що конденсуються в момент виникнення контактів між їхніми частками у водостійкі каменеподібні тіла значної міцності, яку вони здатні підвищувати як на повітрі, так і у воді [1]. Механізм контактно-конденсаційного твердіння забезпечує утворення міцного каменеподібного тіла при виникненні контактів між мікрочастками речовини аморфної або нестабільної кристалічної структури без зміни його хімічного складу в результаті фізичних поверхневих явищ. Тому для забезпечення більш міцних контактів між частками таких в'яжучих при їх конденсації необхідно прикласти зовнішній тиск (пресування).

Реалізація таких в'яжучих не зв'язана зі строками тужавлення. Процес твердіння здійснюється миттєво в момент виникнення контактів між частками таких в'яжучих. Надалі міцність штучного каменю зростає у природних умовах та у воді.

Метою дослідження було визначення оптимальних значень тисків пресування при отриманні стінових виробів на основі в'яжучих контактного твердіння та аналіз існуючих теоретичних положень процесів пресування, які використовуються у промисловості будівельних матеріалів, а також в інших галузях промисловості.

\section{Матеріали та методи досліджень}

Попильським Р.Я. та ін. [2] запропонований наступний опис процесів які відбуваються при пресуванні керамічних порошків. На початковій стадії ущільнення відбувається переміщення частинок порошку у напрямку дії тиску пресування та заповнення великих пор. Деформація частинок при цьому практично не відбувається. В результаті істотно збільшується щільність упакування частинок. Площа контактів між частками порошку змінюється незначно, а міцність таких матеріалів залишається низькою. При подальшому збільшенні тиску пресування, частинки порошку вже не можуть вільно переміщатися в пори, і починається деформація частинок порошків. Спочатку сколюються всі уступи на поверхні частинок (тендітна деформація), потім, останні, під дією сили стискання затікають у пори (пружна та пластична деформаціï). Зі збільшенням тиску пресування ступінь деформації частинок порошку зростає i, як наслідок, збільшується кількість контактів між частинками порошку. При цьому, змінюється гранулометричний склад порошку - збільшується число зерен за рахунок дроблення та з'явля- ються більш дрібні частинки за рахунок руйнування під дією високих напруг у місцях контакту [2].

Аналогічні положення, щодо процесів які проходять при ущільненні порошків, відображені у роботах Куніна Н.Ф., Юрченко Б.Д., Бережного А.С. та інші [3 - 5].

Технологія пресування порошкоподібних матеріалів передбачає отримання виробів з визначеними характеристиками щодо їх міцності та середньої густини. При проведенні аналізу процесів, що відбуваються при пресуванні зручно користуватися математичними виразами (рівняннями пресування), що розкривають функціональну залежність між тиском та густиною отриманого при цьому матеріалу $(\gamma-P)$. За допомогою рівнянь пресування, для кожного порошку або групи споріднених по фізико-хімічним параметрам порошків можливо визначити найбільш економічні параметри режимів пресування $[2,3]$.

При визначенні впливу різних факторів на процеси пресування порошкових матеріалів використовують різні рівняння пресування [2 - 4]. Для порошкових мас, які використовуються в технології керамічних матеріалів, застосовується формула Бережного А.С., а для металічних порошків - формула, що запропонована Бальшеним М.Ю.

Основне рівняння Бережного А.С. має вигляд

$$
\Pi=a-b \cdot \lg P,
$$

де $\Pi$ - пористість, \%; $a$ та $b$ - константи, які визначають певні властивості даного порошку; $P$ - тиск пресування, кг/ $\mathrm{cm}^{2}$.

Бальшиним М.Ю. запропоноване рівняння, яке визначає кількісну залежність густини отриманого зразка від тиску пресування

$$
\lg P=-m \lg \beta+\lg P_{\max },
$$

де $P$ - тиск пресування; $P_{\max }-$ максимальний тиск пресування, при якому пористість зразка наближається до нульового значення; $m$ - постійна, що враховує природу матеріалу; $\beta$ - відносний об'єм зразку.

3 рівнянь пресування порошкових матеріалів які часто зустрічаються в іноземній літературі необхідно виділити рівняння Хекеля (Heckel) [3, 6]. Рівняння виражає залежність густини порошкових матеріалів від прикладеного тиску

$$
\ln [1 /(1-\rho)]=k \cdot P+A,
$$

де $\rho$ - відносна густина при тиску $P$; $P$ - прикладений тиск; $A$ та $k$ - константи.

3 наведених рівнянь пресування можна констатувати, що вони, як правило, є апроксимацією екс- 
периментально отриманих залежностей показника пресування - густини (відносної густини, пористості та ін.) від тиску пресування. При цьому, у своій більшості, основні фізико-механічні характеристики отриманого матеріалу багато в чому будуть визначатися наступними операціями їх обробки, а саме режимами - випалу чи спікання (для керамічних і металевих порошків) або автоклавної обробки (для силікатних матеріалів). Тому, в більшості рівнянь пресування, критерій оцінки міцності матеріалу одержаного при пресуванні, практично не знайшло відображення.

Механічна міцність матеріалів отриманих методом пресування зростає по мірі збільшення ступеню ущільнення. На значення цього параметру впливають різні фактори: розмір частинок порошку, пружно-пластичні властивості і головне - сили взаємодії між складовими частинками порошку $[1-3,5]$. Для в'яжучих контактно-конденсаційного твердіння процес пресування повинен забезпечити ущільнення матеріалу достатнього для утворення між частинками порошку фазових контактів [1]. При цьому, кількість таких контактів буде визначати основні фізико-механічні властивості отриманого матеріалу (міцність, водостійкість та ін.).

3 відомих математичних рівнянь які відображають залежність міцності матеріалів отриманих методом пресування від тиску можливо виділити наступні.

Так, для мало пористої кераміки запропоновано емпіричне рівняння

$$
\sigma=\sigma_{0}(1-\varepsilon)^{m}
$$

де $\sigma$ - міцність при стиску; $\sigma_{0}-$ межа міцності, матеріалу отриманого екстраполяцією до $\varepsilon=0 ; \varepsilon-$ доля пористості в об'ємі матеріалу; $m$ - коефіцієнт.

Белоусовим А.А. [3] запропонована формула

$$
\lg \sigma=\alpha\left[(\lg ] P-\lg P_{0}\right)+\lg \sigma_{0},
$$

або

$$
\sigma P^{-\alpha}=\text { const, }
$$

де $\sigma$ - міцність на стиск, МПа; $P$ - тиск пресування, МПа; $P_{0}$ - початковий тиск пресування, який відповідає міцності зразка $0,2 \mathrm{MПа;} \sigma_{0}$ - початкова міцність при тиску $0,2 \mathrm{MПа;} \alpha$ - константа.

Оскільки суттєва відмінність виробів виготовлених з в'яжучих контактно-конденсаційного твердіння є утворення штучного каменя, в якому їх міцність та повна водостійкість формується відразу після пресування, без послідуючої термічної обробки, визначення залежності $\sigma-P$ для таких матеріалів має практичний інтерес.
Відповідно до [2 - 4] процес пресування порошкоподібних матеріалів проходить в три стадії. 3 урахуванням процесів, які обумовлюють твердіння контактно-конденсаційних в'яжучих найбільш ефективною, є друга стадія процесу ущільнення, при якій робота затрачена на ущільнення матеріалу до заданої щільності буде мінімальною, оскільки повністю припадає на ущільнення матеріалу без його руйнування. Визначення інтервалів такої зони дозволить при заданих значеннях міцності матеріалу та середньої густини, визначати необхідний робочий тиск пресування при виробництві виробів.

Для визначення оптимальних значень тисків пресування при отриманні виробів на основі в'яжучих контактного твердіння в якості дослідних систем були використані дані експериментальних досліджень, які отримані на зразках виготовлених на основі гідросилікатів кальцію з використанням в якості вихідних компонентів вапна та золи-винесення ТЕС, які відрізняються кількісним співвідношенням. Так для суміші 1 це співвідношення складає $1: 2$, для суміші $2-1: 4$

\section{Результати та їх обговорення}

На рис. 1 представлені залежності середньої густини зразків виготовлених із сумішей 1 та 2 від тиску пресування в звичайній (а) та логарифмічній системі координат (б). Характери кривих в логарифмічних координатах близькі до прямих і можуть бути записані у вигляді рівнянь (коефіцієнт регресії $\left.R^{2}=0,9985\right)$

$$
\begin{aligned}
& \text { для суміші } 1: \mathrm{y}_{1}=0,113 \mathrm{x}+3,012 \text {; } \\
& \text { для суміші } 2: \mathrm{y}_{2}=0,085 \mathrm{x}+3,098 \text {. }
\end{aligned}
$$

Визначені рівняння в математичній інтерпретації мають наступний вигляд

$$
\lg \gamma=\alpha_{\text {пр }} \lg \frac{P}{P_{0}}+\lg \gamma_{0}
$$

або

$$
\gamma P^{-\alpha_{\text {пр }}}=\mathrm{const}
$$

де $\gamma$ - середня густина; $P$ - тиск пресування, МПа; $P_{0}-$ мінімальний тиск пресування; $\gamma_{0}-$ середня густина зразків при $P_{0} ; \alpha_{n p}-$ постійна пресування для кожної суміші, яка визначається за формулою

$$
\alpha_{\text {пр }}=\frac{\lg \frac{\gamma}{\gamma_{0}}}{\lg \frac{P}{P_{0}}},
$$



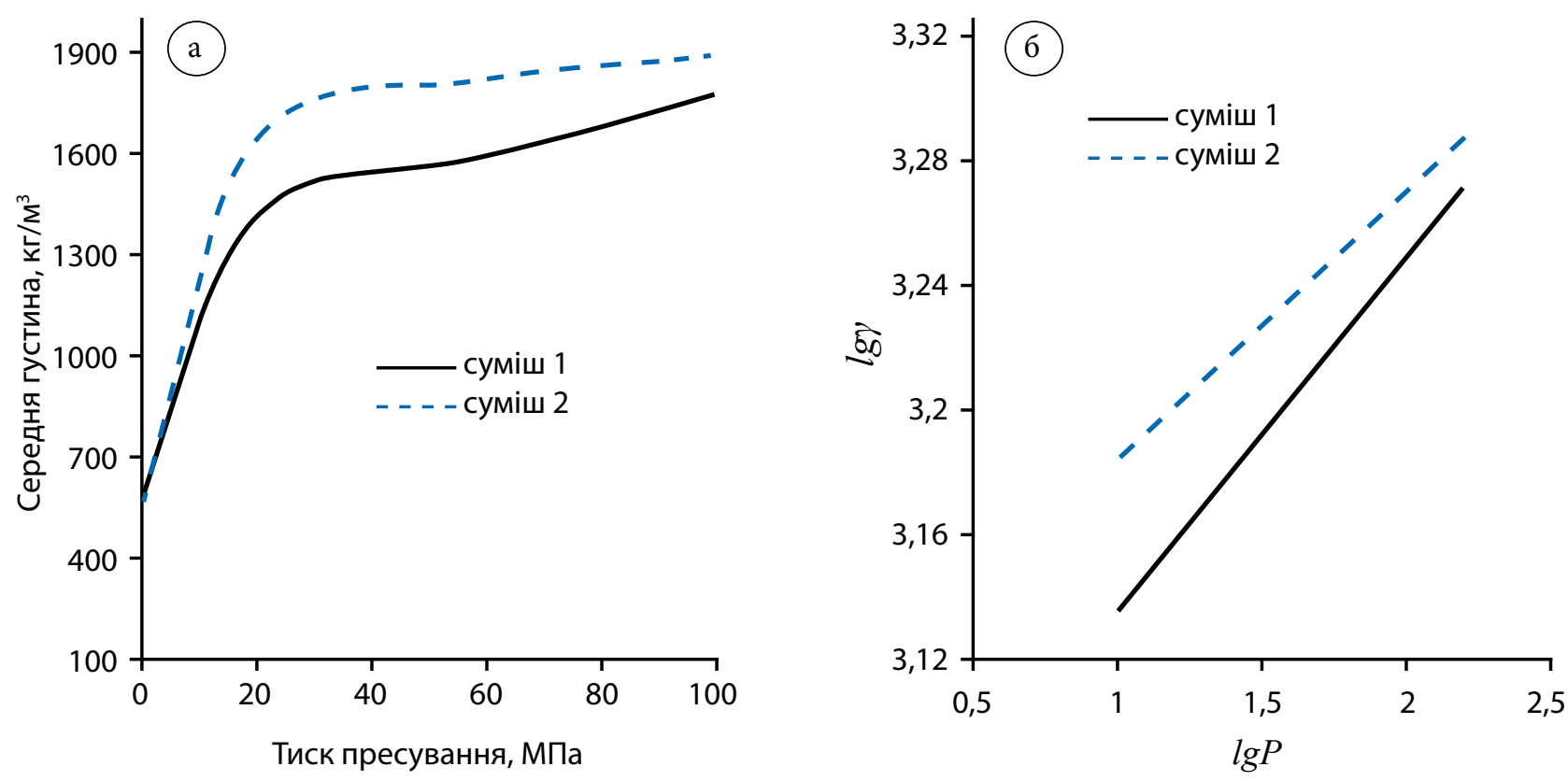

Рис. 1. Залежності середньої густини зразків від тиску пресування в звичайній (а) та логарифмічній системі координат (б)

Для суміші 2 постійна пресування $\left(\alpha_{n p}\right)$ має значення 0,085, а для суміші $1-0,113$.

З урахуванням специфічних властивостей в'яжучих контактно-конденсаційного тверднення, у практичному плані значний інтерес представляє встановлення залежності значень механічної міцності, одержуваного матеріалу, від тиску пресування.

Для цього був проведений аналіз залежності міцності при стиску зразків виготовлених 3 сумішей 1 та 2 від тиску пресування. Аналіз цих залежностей показує, що вони носять лінійний характер і можуть бути записані у вигляді рівнянь.

Так для зразків виготовлених з суміші 2 рівняння має вигляд

$$
\begin{aligned}
& \sigma_{2}=0,3788 P+0,875 \\
& \left(\text { коефіцієнт регресії } R^{2}=0,9927\right),
\end{aligned}
$$

для зразків виготовлених з суміші 1

$$
\begin{aligned}
& \sigma_{1}=0,2975 P+1,45 \\
& \left(\text { коефіцієнт регресії } R^{2}=0,9966\right)
\end{aligned}
$$

де $\sigma$ - міцність на стиск, МПа; $P$ - тиск пресування при отриманні зразків, МПа.

Результати розрахунків проведених за формулами (12) та (13) приведені на рисунку 2. Аналіз значень, отриманих експериментально та розрахунковим методом, залежності $\sigma-P$, свідчать про їх достатньо високий ступінь співпадіння за значеннями.

Практичні значення отриманих рівнянь пресування полягають в тому, що вони дозволяють вибрати значення тиску пресування для отримання стінових матеріалів в межах існуючих для них марок, а саме від M75 до М300 і отримання виробів з заданими фізико-механічними властивостями (середньою густиною, водопоглиненням та ін.).

Суттєвою відмінністю виробів з в'яжучих контактно-конденсаційного твердіння, є зростання міцності у часі, на відміну від виробів виготовлених за автоклавною технологією. Визначення цих закономірностей, а саме зміну міцності в часі та в залежності від умов твердіння має практичний інтерес. Так, на рис. 2 б представлена залежність $\sigma-P$ для зразків у віці 28 діб.

Крім цього, практичний інтерес матимуть встановлені залежності зміни параметрів міцності на стиск від середньої густини, тобто залежність виду $\gamma-\sigma$. Встановлення такої залежності можливо або за рахунок рішення системи рівнянь, які відображають встановлені раніше залежності $\gamma-P$ та $\sigma-P$ для кожного з видів дослідних композицій, або визначання такої залежності за даними отриманими експериментально.

На рисунку 3 представлені залежності середньої густини зразків від їх міцності на стиск, які були отримані відразу після пресування. Вказані залеж- 

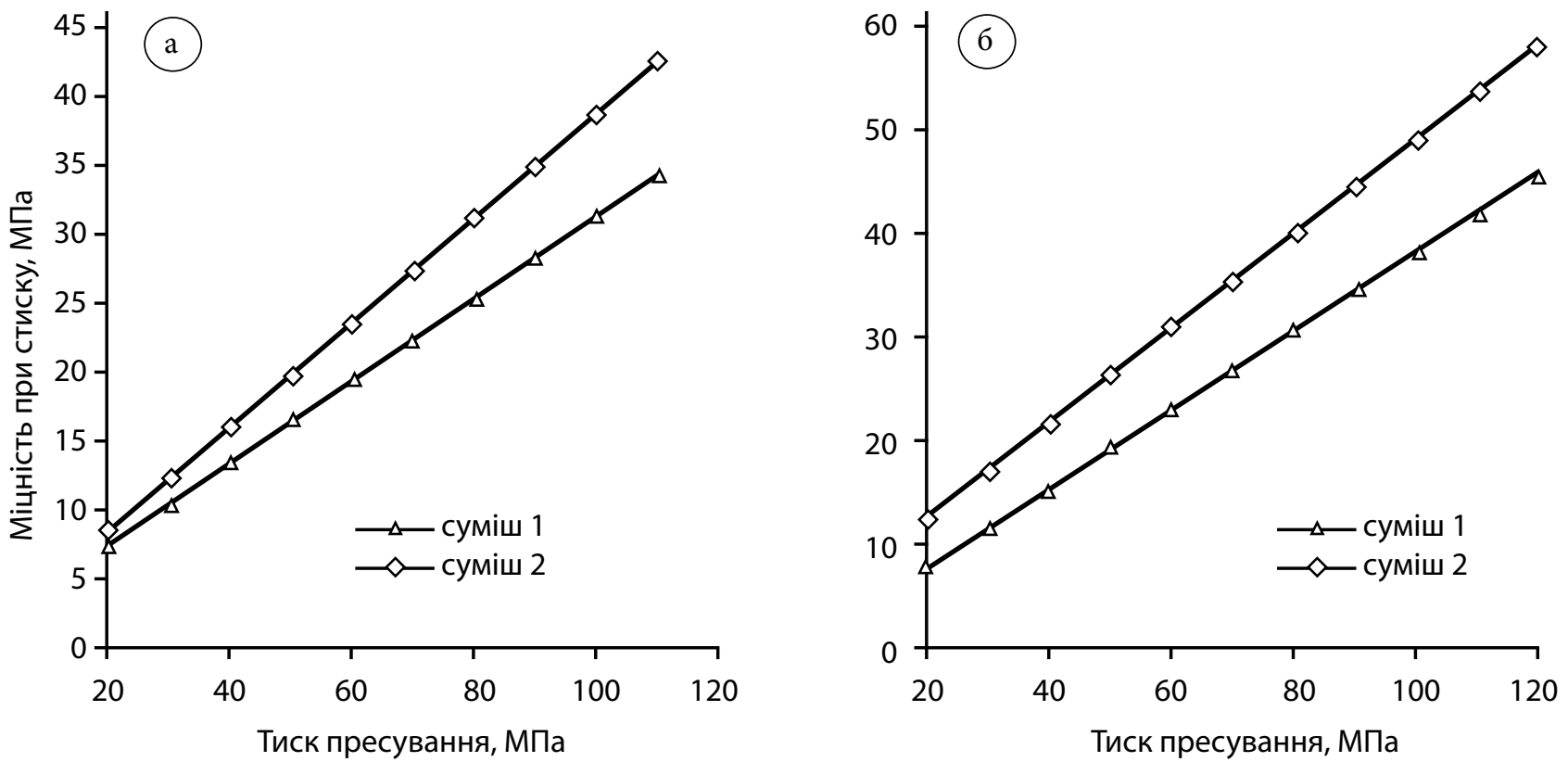

Рис. 2. Залежності начальної (відразу після пресування) міцності на стиск зразків від тиску пресування розрахованих за формулами (а) та через 28 діб твердіння (б)

ності мають лінійний характер, їх можна відобразити у вигляді наступних рівнянь. Для зразків виготовлених з суміші 2 ця залежність має вигляд

$$
\begin{aligned}
& \gamma_{2}=14,642 \cdot \sigma+1310,7 \\
& \left(\text { коефіцієнт регресії } R^{2}=0,9974\right) \text {, }
\end{aligned}
$$

а для зразків виготовлених з суміші 1

$$
\begin{aligned}
& \gamma_{1}=8,1971 \cdot \sigma+1596,5 \\
& \text { (коефіцієнт регресії } R^{2}=0,975 \text { ). }
\end{aligned}
$$

Графічні відображення визначених рівнянь $\gamma-\sigma$ приведені на рис. 3.

Встановлені залежності, які визначають основні параметри отриманих матеріалів від тиску пресування були визначені в досить широкому діапазоні тисків пресування - від 20,0 до 100,0 МПа. Вказаний діапазон тисків має практичне застосування в різних галузях промисловості, в т.ч. при виробництві штучних будівельних матеріалів (наприклад, в технології гіперпресування). Тому визначення оптимальних значень цього параметру при виготовленні стінових виробів на основі в'яжучих контактно-конденсаційного твердіння є визначальним.

Як було відмічено раніше, процес ущільнення порошкоподібних речовин при пресуванні проходить три стадії. 3 аналізу робіт $[2-4,6]$ що до визначення ефективності дії тисків на основні фізико-ме- ханічні властивості матеріалів отриманих методом пресування, є друга стадія, процес ущільнення при якій проходить за рахунок пластичних деформацій. 3 існуючих рівнянь пресування, що дають можливість розділити вказані процеси пресування на певні стадії, є рівняння Хекеля.

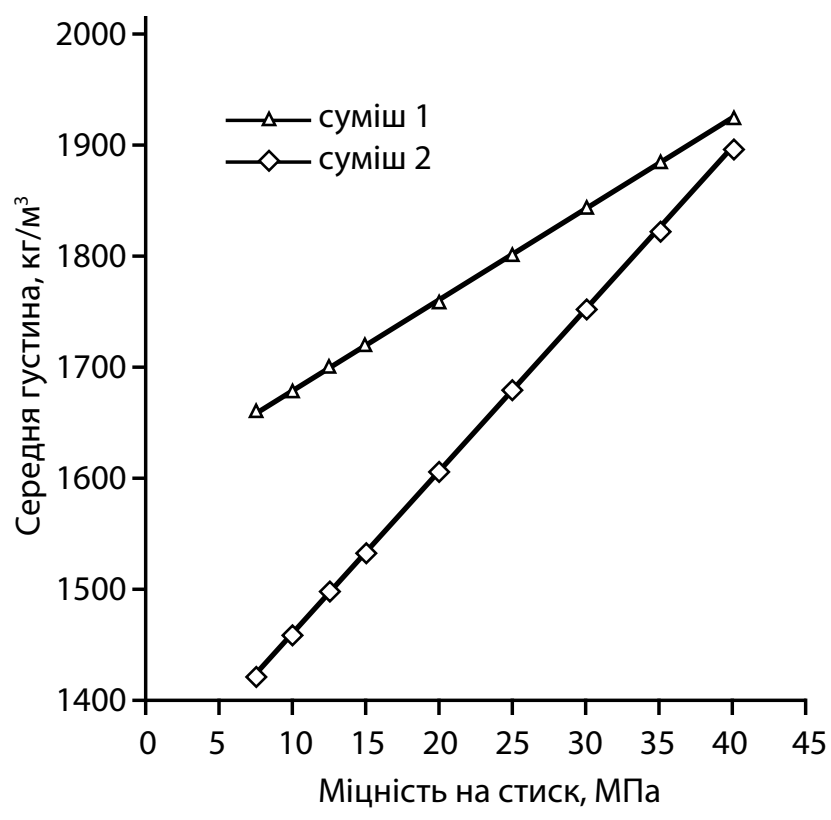

Рис. 3. Залежності середньої густини зразків від міцності на стиск випробуваних відразу після пресування 
Для визначення основних параметрів рівняння Хекеля у графічному вигляді були використані дані отримані експериментально та рахунковим методом.

На рис. 4 приведена залежність відносної густини зразків від тиску пресування. Основні значення складових рівняння Хекеля становлять: $\alpha-14^{0} 60^{\prime}$, $k=0,2608, A=1,63$, вихід тиску $\left(P_{y}\right)=1 / k=1 / 0,2608$ $=3,834, \rho_{o}=0,332, \rho_{B}=1,308$.

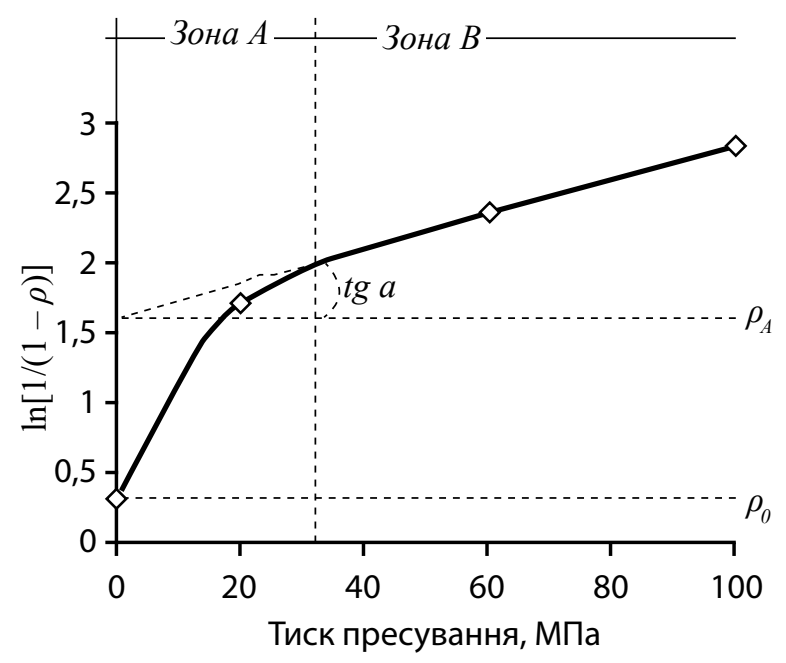

Рис. 4. Залежність відносної густини зразків від тиску пресування визначених за рівнянням Хекеля

Значення виходу тиску $P_{y}$ має низьке значення, що вказує на низький опір дії тиску, і добре ущільнення та легкий стиск матеріалу. 3 графіку видно, що починаючи 3 тиску 32 МПа існує практично лінійна залежність відносної густини зразків від прикладених тисків. Це вказує на те, що ущільнення головним чином проходить за рахунок пластичної деформації. Параметр $\rho_{o}$ характеризує початок фази ущільнення, яке проходить за рахунок перебудови та фрагментації часток, і характеризує момент, коли дія тиску дорівнює нулю. Чим більше значення $\rho_{0}$, тим більша ступінь упаковки.

Лінійна ділянка рівняння Хекеля, яка характерна для пластичної деформації матеріалів починається при тиску вище 32,0 МПа. В діапазоні вибраних в дослідженнях тисків пресування до 100,0 МПа вона має лінійну залежність. Таким, чином у вибраному діапазоні визначено тільки дві зони характерні для рівняння Хекеля - зону А та початок зони В. Для визначення тисків пресування, які характеризують кінець зони В та початок зони $\mathrm{C}$ - зони дії пружних деформацій, було побудоване графічне рівняння Хекеля за результатами значень середньої густини зразків від тиску пресування визначених за формулою (10).

\section{Висновки}

Отримані дані для тиску пресування, які характеризують дію пластичних деформацій (зона В), для дослідних сумішей знаходиться в інтервалі від 32,0 МПа до 158,0 МПа. Збільшення тиску вище вказаного призводить до переходу пластичних деформацій в пружні деформації, при яких ущільнення проходить за рахунок руйнування часток під дією високих тисків. Таким чином для дослідних сумішей на основі в'яжучих контактно-конденсаційного твердіння встановлено, що для забезпечення максимально ефективної дії тисків (які забезпечують пластичні деформації при ущільненні і забезпечують найбільш щільну упаковку частинок порошку), існує межа робочих тисків в інтервалі від 40 до 150 МПа.

\section{References}

1. Глуховский, В.Д., Рунова, Р.Ф., Максунов, С.Е. Вяжущие и композиционные материалы контактного твердения. - К.: Вища школа. - 1991. - 243 с.

2. Попильский, Р.Я., Пивинский, Ю.Е. Прессование порошкообразных керамических материалов. - М.: Металлургия. - 1983. - 176 с.

3. Белоусов, В.А., Вальтер, М.Б. Основы дозирования и таблетирования лекарственных порошков. М.: Медицина. - 1980. -216 с.

4. Кунин, Н.Ф., Юрченко, Б.Д. Закономерности уплотнения порошков из различных материалов. Порошковая металлургия. - №. 6 (18). - 1963. C. 3 - 10

5. Тимамев, В.В., Сулименко, Л.М., Альбаи, Б.С. Агломерация порошкообразных силикатных материалов. - М.: Стройиздат. - 1978. - 136 с.

6. Oluwatoyin, A. Odeku and Oludele A. Itiola. Compaction Properties of Three Types of Starch. ServicesIranian Journal of Pharmaceutical Research 6. 2007. - C. 17 - 23. 